\title{
Use of laser-induced break spectroscopy for the determination of major and trace elements in Zanthoxylum armatum
}

\author{
Shabnam Shahida ${ }^{1} \cdot$ Muhammad Imran Khan $^{2} \cdot$ Sadaf Azad $^{1} \cdot$ Nasar Ahmed $^{3} \cdot$ Mushtaq Hussain Lashari $^{4}$. \\ Majeda Khraisheh ${ }^{5}$. Fares Almomani ${ }^{5}$. Shagufta Zafar ${ }^{6}$
}

Received: 4 January 2020 / Accepted: 27 March 2020 / Published online: 23 April 2020

(C) The Author(s) 2020

\begin{abstract}
Zanthoxylum armatum (ZA) is a medicinal plant (MP) that is widely distributed in hilly and moist areas and has a different medical effect on human curative functions. Laser-induced breakdown spectroscopy (LIBS) was employed as a simple, easy, and accurate method to analyze the elemental profile of Zanthoxylum armatum (ZA) (timur). Various elements present in different parts of ZA were identified including sodium, magnesium, calcium, potassium, titanium, iron, barium, aluminum, lithium, and silicon. The proposed method accuracy was found to be comparable with high technical complicated lab equipment The concentrations of these elements were determined and were found to be below the toxic level.
\end{abstract}

Keywords LIBS · Elemental profile · Zanthoxylum armatum · Quantitative analysis · Promising remedy

\section{Introduction}

Medicinal plants (MPs) are considered the most important sources of medicines $[1,2]$. Reports show that up to 80,000 of MPs are used for the extraction of different medicines [3, 4]. Moreover, different communities use MPs as traditional medicine, livelihood and for health security $[5,6]$. As per the World Health Organization (WHO) report, over $80 \%$ of the world's population relies on active ingredients extracted from MPs as the main health care aids [7, 8]. In addition, about $40 \%$

Shabnam Shahida

shabnamshahida01@gmail.com

Muhammad Imran Khan

raoimranishaq@gmail.com

Sadaf Azad

Sadaf.azad4@yahoo.com

Nasar Ahmed

nasarahmed@yahoo.com

Mushtaq Hussain Lashari

mushtaqlashary@gmail.com

Majeda Khraisheh

m.khraisheh@qu.edu.qa

Shagufta Zafar

shg_zf@yahoo.com of the pharmacological industries depend on MPs to extract active ingredients as the MPs are considered a rich source of essential inorganic elements and antioxidants $[9,10]$.

MPs, in general, contain major and trace elements that have a crucial role in the metabolic reactions of humans and plants. These elements can participate in reactions responsible for the formation of active compounds and play a significant role in many physiological functions $[11,12]$. In addition, MPs contain natural products that are more accustomed to the human body; therefore, they are used in different complementary and

1 Department of Chemistry, University of Poonch, Rawalakot, Azad Kashmir, Pakistan

2 School of Chemistry and Material Science, University of Science and Technology of China, Hefei 230026, Anhui, People's Republic of China

3 Department of Physics, University of Azad Jammu and Kashmir, Muzaffarabad, Pakistan

4 Department of Zoology, The Islamia University of Bahawalpur, Bahawalpur 63100, Pakistan

5 Department of Chemical Engineering, College of Engineering, Qatar University, Doha, Qatar

6 Department of Chemistry, The Government Sadiq College Women University, Bahawalpur 63000, Pakistan

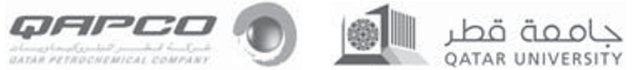


alternative therapist treatments. However, in some cases, toxic elements may also be present in MPs and, in most cases, may result in poisonous effects due to their accumulation in the human body [13]. Therefore, qualitative and quantitative analysis of essential and toxic elements present in the MPs is an essential task to understand their remedial options.

Among the different MPs that are extensively used, Zanthoxylum armatum (ZA) which belongs to the family of Rutaceae is considered one of the genera that possesses high medicinal value. The ZA contains volatile oil with active constituents such as linalool, limonene, and lignin that can be employed as carminative, stomachic, and anthelmintic as well as in the treatment of toothache. Different studies have shown that ZA possesses antilarvicidal, antifungal, hepatoprotective and allelopathic properties.

Locally ZA is known as timur and in English as winged prickly ash. ZA grows as a large spiny shrub tree and it is commonly distributed in Kashmir, India, Bhutan, and hot areas of Northeast India at altitudes of about $2500 \mathrm{~m}$. It usually grows abundantly in the hilly and moist areas. ZA has trifoliate leaves with winged leaf stalks. The leaflets are ovate- or elliptic-like, a little or fully toothed with oblique base. The tree has yellow minute flowers have 6-8 sepals. Large anthers and 6-8 stamens are present in male flowers, while 1-3-celled ovaries are present in the female flower. Fruits are enclosed inside pericarp which split into two on ripening. Seeds are shiny black and round having a diameter of about $3 \mathrm{~mm}$. The flowering period starts in March and ends in April [14, 15]. The fruits, seeds, and bark of this plant are extensively used in stomachic, caminative, and anthelmintic system of medicine [16].

Different analytical methods were employed to identify the composition of ZA. Shah [17] used GC and GC/MS and reported that the oil content of ZA contains $72 \%$ linalool, $12.2 \%$ methyl cinnamate, $6.2 \%$ of limonene, and $5.3 \%$ of $\beta$ phellandrene. Kumar et al. [18] also used the GC-MS to analyze the chemical composition and larvicidal activity of ZA against diamondback moth, Plutella xylostella. Bisht and Chanotiya [19] employed the capillary gas chromatography (GC-FID) and gas chromatography-mass spectrometry (GCMS) to identify the major classes of compounds found in the leaf of ZA. Acyclic and menthane monoterpenoids as well as simple alcohols, aldehydes, and ketones were the main products identified. In addition, the study showed a high proportion of non-terpenic acyclic ketones, notably 2-undecanone and 2-tridecanone and the low abundance of undec-10-en-1al and p-phellandren-8-ol. But the techniques used for these analysis are complicated, expensive and time consuming. A simple, easy, and effective tool and/or procedure that can be used to identify the ZA composition of different parts of ZA is lacking and requires further research work. Therefore, the present work reports on the use of laser-induced breakdown spectroscopy (LIBS) as an elemental analysis of ZA. The present work is unique and important because it reports for the first time an easy, simple, and accurate method that can be used to analyze different parts (root, stem, leaves, and fruit) of ZA with high accuracy compared with difficult, expensive, and time-consuming lab techniques. Moreover, the proposed method can be used to determine elemental analysis of the nearby soil which helps in identifying and determining the possible source of elements. The LIBS is an emerging sensitive analytical technique that is accurate, has simple preparation requirements, and can be performed in a short time [20, 21]. The LIBS is characterized by determining the operating temperature and electron density which is an essential parameter to understand the effect of method parameters on the samples. The method parameters depend on laser irradiance, wavelength, pulse duration, target material, atmospheric conditions, space, and time. Different studies have shown that using an optically thin LIBS, the excitation temperature that controls the distribution of energy level excitation can be determined by Boltzmann equation [22, 23], while the ionization temperature can be estimated by ionization equilibrium calculations using Saha equation which is known as plasma [24, 25]. In the present work, tests were conducted to determine major and trace elements of an important medicinal plant ZA collected from the district Bagh, Azad Jammu and Kashmir, Pakistan.

\section{Material and methods}

\subsection{Sample preparation}

Different parts of ZA including roots, stem, leaves, and seeds were collected from District Bagh, Azad Kashmir, Pakistan, and used in the analysis. Soil samples were also collected from near the roots of plants. Collected samples were dried in direct sunlight and cut to small pieces with an average diameter of $20 \mathrm{~mm}$ and thickness of $2 \mathrm{~mm}$. Then, pellets were prepared by placing $2 \mathrm{~g}$ of the pieces in the hydraulic press and applying 25,000 psi pressure to the sample.

\subsection{Experimental setup}

The spectral analysis of ZA was conducted in a high-power Q-switched Nd: YAG laser (Brilliant-B Quantel, France). This device is capable of delivering $200 \mathrm{~mJ}$ energy at $532 \mathrm{~nm}$ and $400 \mathrm{~mJ}$ at $1064 \mathrm{~nm}$, in $5 \mathrm{~ns}$ pulse duration, and $10 \mathrm{~Hz}$ repetition rate. The energy of laser pulse was varied by varying the Q-switch delay and measured with the energy meter (Nova-Quantal, France). The green laser having the pulse energy of 50-100 $\mathrm{mJ}$ was focused on the surface of the pellet through a $20-\mathrm{cm}$ focal length of the quartz lens (convex). The spot size of the laser beam was about $0.10 \pm 0.01 \mathrm{~cm}$ and the corresponding laser flounced 
about $6-12 \mathrm{~J} / \mathrm{cm}^{2}$. The samples were placed on a rotating stage to record the optical emission spectra from different areas of the pellet and to provide a fresh surface to every laser shot. The distance between the sample and the lens was kept less than the focal length of the focusing lens in order to prevent the breakdown of air in front of the sample. The light was emitted from the plasma plume and captured by an optical fiber (high $-\mathrm{OH}$, the core diameter of about $600 \mu \mathrm{m})$ having a collimating lens $\left(0-45^{\circ}\right.$ field of view) placed normal to the plasma plume. The emitted radiation was registered by a set of four spectrometers (Avantes, Holland) each having $10-\mu \mathrm{m}$ slit width and covering the wavelength range of $250-880 \mathrm{~nm}$. The LIBS software was used to correct the emission signal by subtracting the dark signal from the observed emission signal. The emitted radiation was guided to the spectrometer through fiber optics and then detected by the system software. The light was collected in the form of panels by the detector and finally saved as an intensity data. The LIBS detection system was connected with the optical fiber for measuring the plasma emission. Finally, the emission spectrum of the sample material was completely analyzed using the NIST Atomic Data Base [26].

\section{Results and discussion}

\subsection{Emission studies}

Qualitative analysis of all the samples was based on the comparison between the emission lines observed by each element compared with the spectral lines from NIST database. Only the spectral lines with relatively high intensity were considered. The emission spectra were tested in the wavelength range of 250 to $880 \mathrm{~nm}$. The spectra are further divided into small portions to completely identify the spectral lines. The emission lines of ten different elements such as $\mathrm{Ca}, \mathrm{Na}, \mathrm{Mg}, \mathrm{K}, \mathrm{Fe}, \mathrm{Si}, \mathrm{Al}, \mathrm{Li}, \mathrm{Ti}$, and $\mathrm{Ba}$ are characterized in all parts of the plant. Figure 1 a shows the emission spectra in the wavelength of 250 to $300 \mathrm{~nm}$. The spectra showed 30 peaks which were identified to be ionized Fe (II). The three lines at $271.90 \mathrm{~nm}, 292.91 \mathrm{~nm}$, and $298.47 \mathrm{~nm}$ were identified to belong to neutral $\mathrm{Fe}$ (I). Cluster lines from 250.69 to $252.85 \mathrm{~nm}$ and the spectral lines at 263.15 and 288.15 were related to $\mathrm{Si}$ (I). $\mathrm{Mg}$ (II) obtained four lines at wavelengths of $279.07 \mathrm{~nm}, 279.55 \mathrm{~nm}, 280.27 \mathrm{~nm}$, and $293.65 \mathrm{~nm}$, while $\mathrm{Mg}$ (II) was observed at $277.98 \mathrm{~nm}$ and $285.21 \mathrm{~nm}$. The peak at $256.79 \mathrm{~nm}$ represents neutral Al (I), while the line at $281.61 \mathrm{~nm}$ belongs to ionized Al (II). The ionized Mn (II) exhibits a line at $257.61 \mathrm{~nm}$. Figure $1 \mathrm{~b}$ presents the second part of the spectrum in the wavelength range from 300 to $400 \mathrm{~nm}$.
This spectrum exhibits several lines of Ti (II) which were observed in the range 316 to $338 \mathrm{~nm}$. The line at $338.18 \mathrm{~nm}$ was related to $\mathrm{Ti}$ (I). Moreover, four spectral lines at $422.67 \mathrm{~nm}, 430.25 \mathrm{~nm}, 443.49 \mathrm{~nm}$, and $445.47 \mathrm{~nm}$ were observed for this part of spectra related to $\mathrm{Ca}$ (I), whereas ionized $\mathrm{Ca}$ (II) depicts four resonance lines at $315.88 \mathrm{~nm}, 317.98 \mathrm{~nm}, 393.36 \mathrm{~nm}$, and $396.84 \mathrm{~nm}$. The spectra also exhibit 13 peaks of neutral $\mathrm{Fe}$ (II). Moreover, it shows six peaks at $305.71 \mathrm{~nm}$, $305.90 \mathrm{~nm}, 308.21 \mathrm{~nm}, 309.27 \mathrm{~nm}, 394.40 \mathrm{~nm}$, and $396.15 \mathrm{~nm}$ for emission lines of neutral Al (I). Figure 1 c shows the third part of the spectrum in the wavelength range 400 to $880 \mathrm{~nm}$. In this portion, bunches of lines from 498 to $503 \mathrm{~nm}$ were related to the emission lines of Ti (I), two peaks at $492.05 \mathrm{~nm}$ and $495.75 \mathrm{~nm}$ belong to neutral $\mathrm{Fe}$ (I), and two emission lines at $588.99 \mathrm{~nm}$ and $589.59 \mathrm{~nm}$ are found for $\mathrm{Na}$ (I). Other spectra were observed at wavelengths of $516.73 \mathrm{~nm}, 517.26 \mathrm{~nm}$, and $518.36 \mathrm{~nm}$ for $\mathrm{Mg}(\mathrm{I}) ; 526 \mathrm{~nm}, 558 \mathrm{~nm}$, and $610 \mathrm{~nm}$ for neutral Ca (I); $585.74 \mathrm{~nm}, 643.90 \mathrm{~nm}, 646.25 \mathrm{~nm}$, $714.81 \mathrm{~nm}$, and $866.21 \mathrm{~nm}$ for $\mathrm{Ca}$ (I), and the line at $854.20 \mathrm{~nm}$ for Ca (II). The two lines at 766.49 and $769.90 \mathrm{~nm}$ belong to K (I). Similarly, it was showed a strong line at $670.77 \mathrm{~nm}$ for $\mathrm{Li}$ (I). It also exhibits lines at $774.41 \mathrm{~nm}$ and 777.19 for $\mathrm{O}$ (I). $\mathrm{H} \alpha$ line is found at a wavelength of $556.26 \mathrm{~nm}$, while the peak at $532 \mathrm{~nm}$ is found to be as a laser line. Finally, various elements found in a soil sample are calcium, magnesium, manganese, titanium, sodium, iron, aluminum, lithium, potassium, barium, and silicon.

Figure 2 a presents the emission spectrum of the root in the wavelength 250 to $550 \mathrm{~nm}$, whereas Fig. $2 \mathrm{~b}$ denotes the second part of the emission spectrum of the root sample in the range 550 to $880 \mathrm{~nm}$. Iron, calcium, magnesium, barium, silicon, potassium, lithium, sodium, and aluminum were found into the roots.

Figure 3 a presents the first part of the emission spectrum of stem samples in the wavelength range 250 to $550 \mathrm{~nm}$, whereas the second part of the emission spectrum of stem sample ranging from 250 to $880 \mathrm{~nm}$ is denoted in Fig. 3b. It has been observed that dominated spectral lines attained in the stem belong to iron, calcium, magnesium, silicon, potassium, lithium, barium, sodium, and aluminum are found in the stem.

Figure 4 a denotes the first part of the emission spectrum of leaf ranging from 250 to $600 \mathrm{~nm}$, whereas Fig. $4 \mathrm{~b}$ exhibits the second part of the emission spectrum of leaf ranging from 600 to $880 \mathrm{~nm}$. Results showed that it exhibits the dominated spectral lines of calcium, magnesium, potassium, sodium, and barium.

The first part of the emission spectrum of fruit samples ranging from 250 to $320 \mathrm{~nm}$ is shown in Fig. 5a, whereas the second part of the emission spectrum of fruit samples ranging from 320 to $880 \mathrm{~nm}$ is shown in Fig. 5b. It has been observed that spectral lines of iron, calcium, magnesium, 

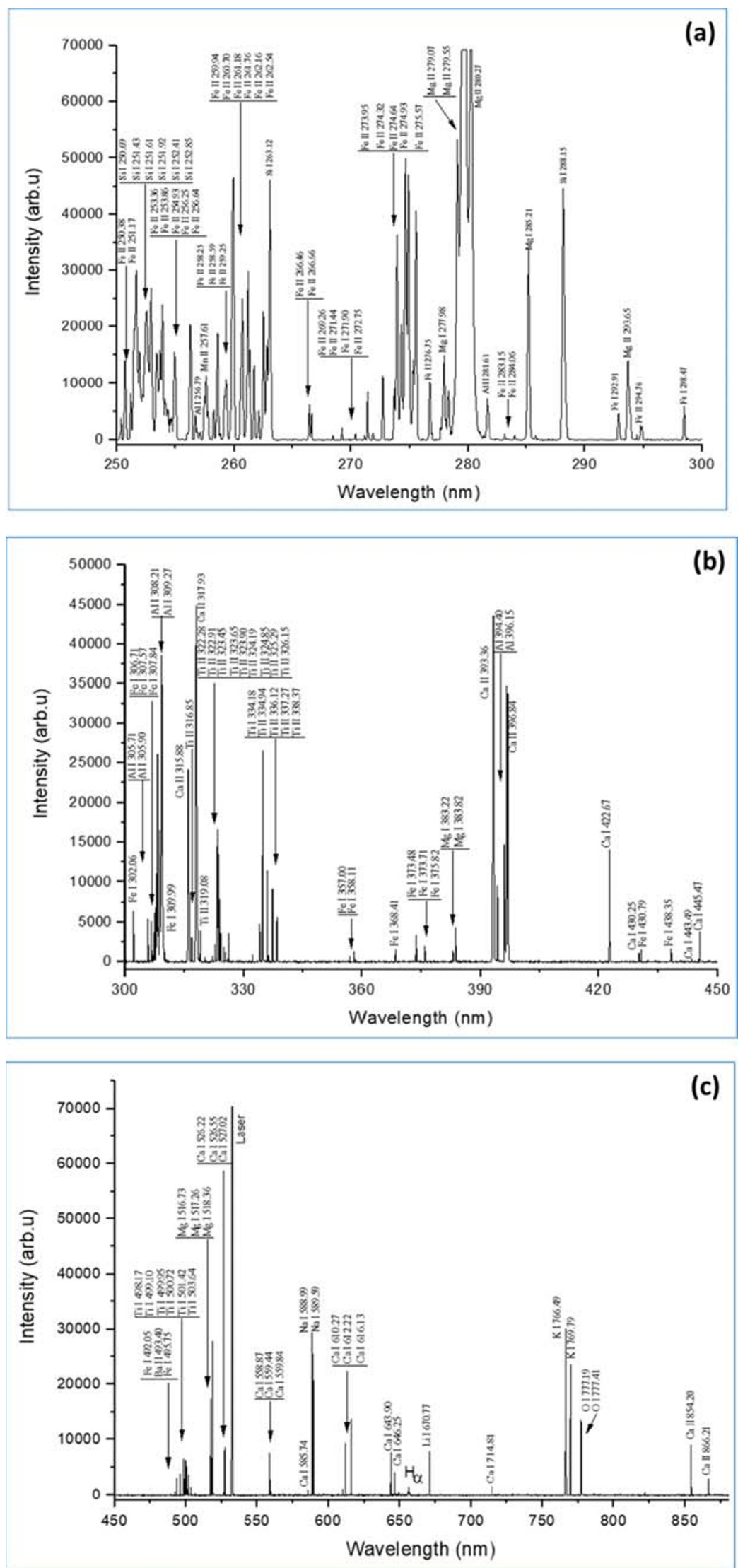

Fig. 1 a Emission spectrum of soil sample ranging from 250 to $300 \mathrm{~nm}$. b $300-450 \mathrm{~nm}$. c $450-880 \mathrm{~nm}$ 
silicon, potassium, lithium, sodium, and aluminum are present into the fruit sample.

\subsection{Measurement of plasma temperature}

The temperature of generated plasma was determined using an accurate and simple procedure known as Boltzmann plot [22, 27]. The plasma temperature was estimated by including the optically thin spectral lines with spectroscopic data from NIST database. The method is based on assuming that the plasma is homogenous with the measurement time interval, and the groundlevel temperature was determined by the ratios of number densities between successive ionization stages [28]. The plasma temperature was determined from the slope of the Boltzmann plot as per Eq. (1)

$$
T=-\frac{g_{\mathrm{k}} \Delta \mathrm{E}}{\ln \left(\frac{I \lambda}{A h c}\right)}
$$

where " $A$ " represents the area under curve, " $h$ " shows Planck's constant $\left(6.626176 \times 10^{-34} \mathrm{~J} \mathrm{~S}\right)$, "c $c$ is for the speed of light $\left(3.00 \times 10^{8} \mathrm{~m} / \mathrm{s}\right), " \Delta$ " represents the energy difference between the two energy levels, " $P$ " shows the intensity, " $\lambda$ " is the wavelength in $\mathrm{nm}$, and " $g_{\mathrm{k}}$ " shows the statistical weight. Table 1 shows the
Fig. 2 a Emission spectrum of root sample ranging from 250 to $550 \mathrm{~nm}$. b $550-880 \mathrm{~nm}$
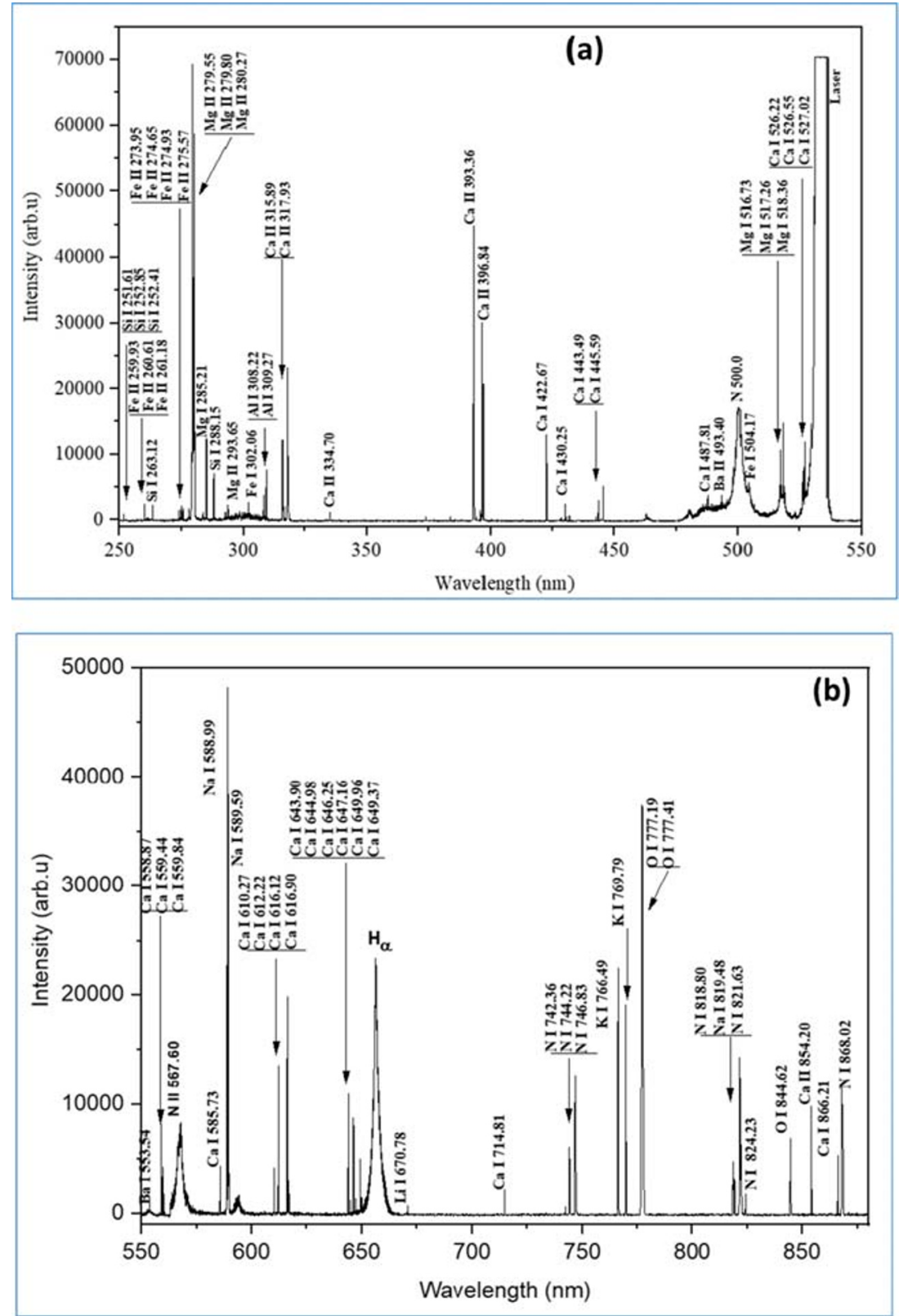
Fig. 3 a Emission spectrum of stem sample ranging from 250 to $550 \mathrm{~nm}$. b $550-880 \mathrm{~nm}$
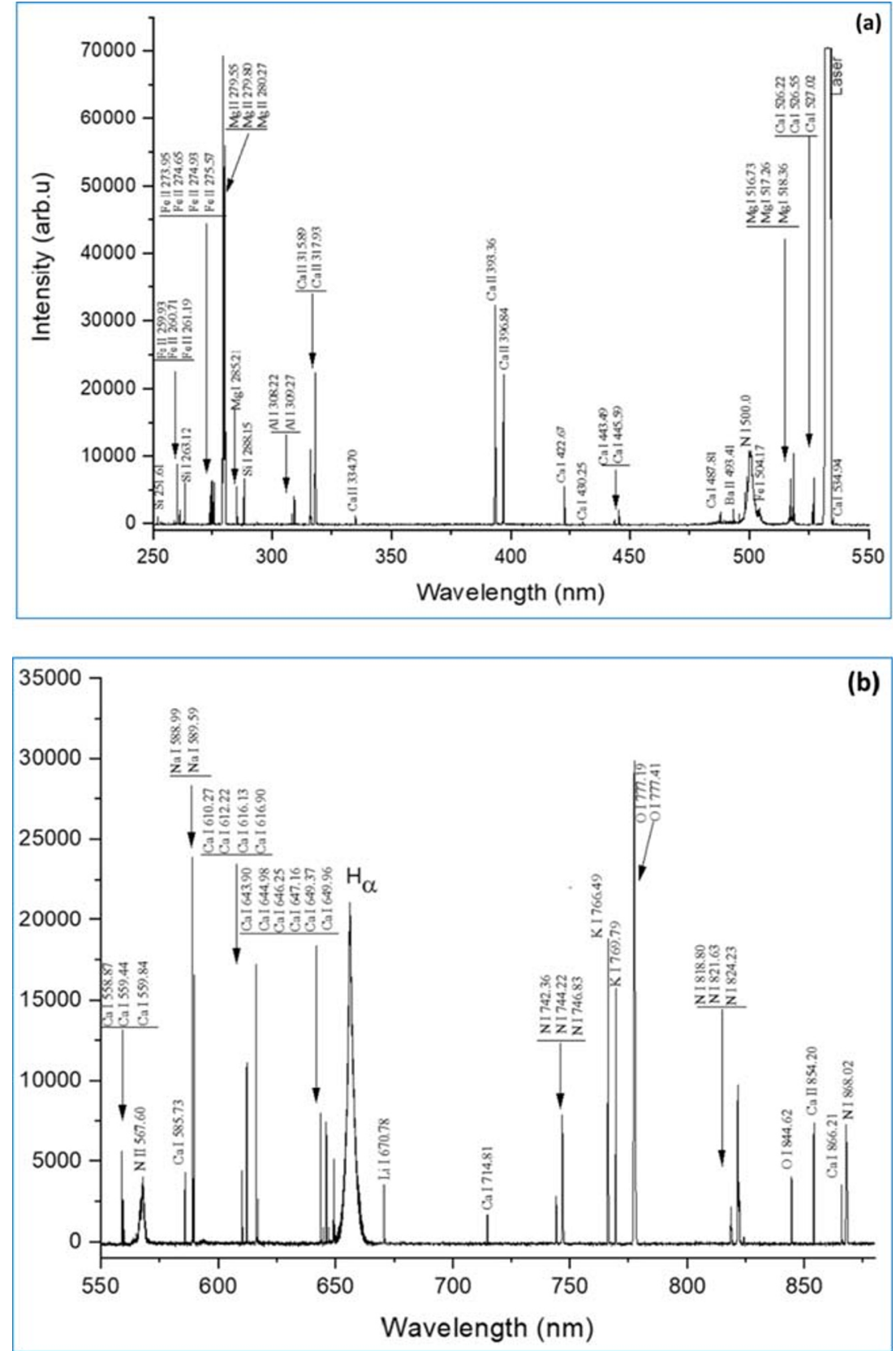

spectroscopic data of optically thin lines of $\mathrm{Ti}$ (II) used in the calculation of plasma temperature.

Spectroscopic data for Ti (II) lines were taken from NIST atomic database, and plasma temperature was estimated as $10,600 \pm 1000 \mathrm{~K}$. Figure 6 shows Boltzmann plot calculated for soil sample. Calculated values of plasma temperatures for all the plant samples are found in the range of (8000-12,000) $\pm 1000 \mathrm{~K}$.

\subsection{Measurement of electron number density}

Electron number density is one of the important thermodynamic parameters used for the characterization of plasma. The Stark broadening parameter is most commonly used to calculate electron number density $(\mathrm{Ne})$ of singly ionized and neutral spectral lines. Electron density can be calculated by finding the full width at half maximum (FHWM) of the Stark-broadened line according to the equation which shows a direct relation between FWHM and electron density. The value of FWHM was determined by performing the Lorentzian fitting of $\mathrm{H} \alpha$ spectral lines of all the samples [29]. Electron number densities of all the plant samples were calculated in the range of as (1.02-9.41) $\times 10^{17} \mathrm{~cm}^{-3}$. Figure 6 depicts the electron number density calculated for the root sample by using the relation given below: 
Fig. 4 a Emission spectrum of leaf sample ranging from 250 to $600 \mathrm{~nm}$. b $600-880 \mathrm{~nm}$
$N_{e}=\frac{1}{2 \omega \mathrm{s}} \Delta \lambda \S \times 1016 \mathrm{~cm}^{-3}$

\subsection{Compositional analysis}

\subsubsection{Calibration-free method}

This method is commonly referred to Boltzmann plot method. Calibration-free LIBS (CF-LIBS) is utilized for
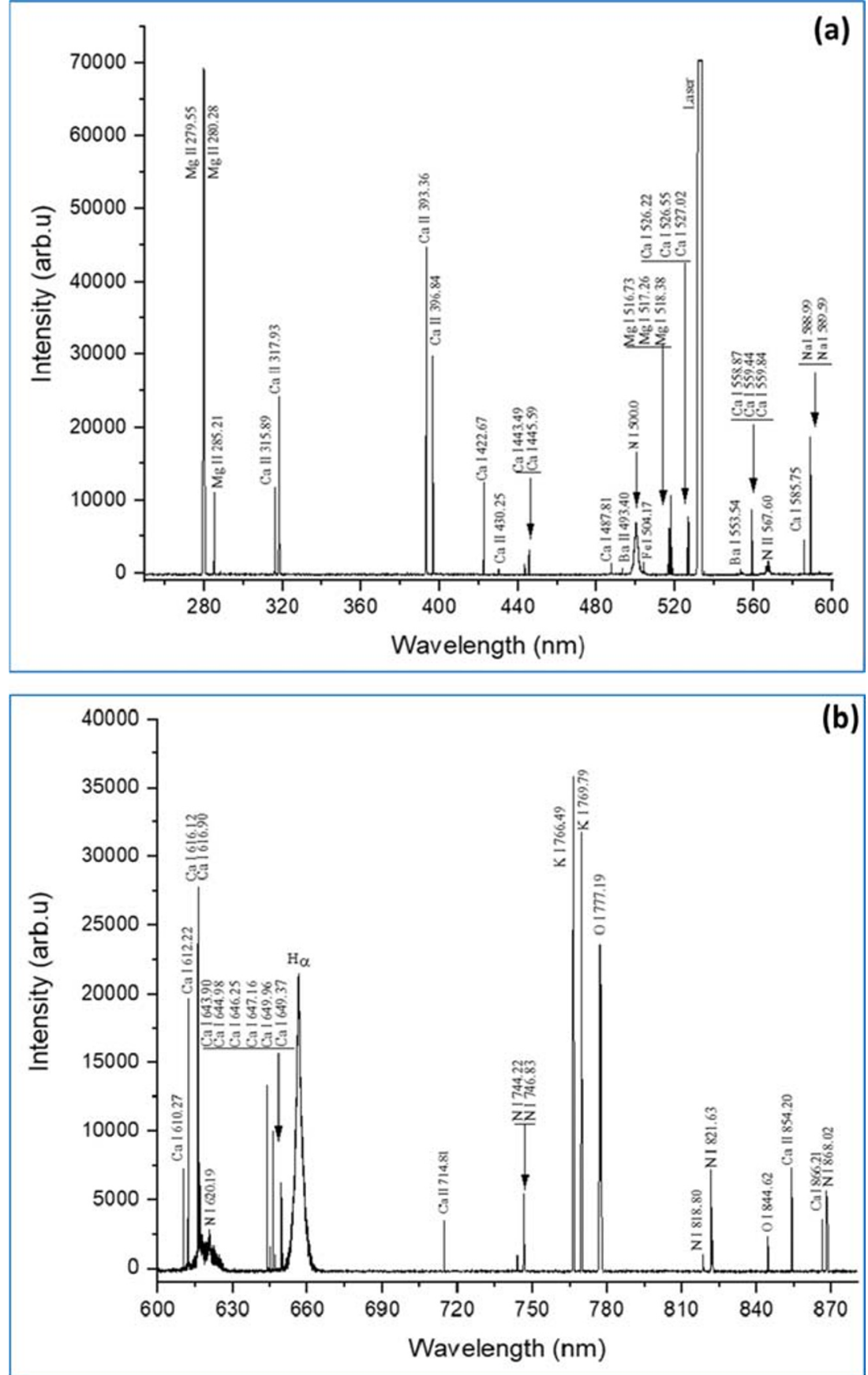

the compositional analysis of sample material after measurement of electron number density and plasma temperature. It is a new technique used for quantitative analysis developed by Gomba and colleagues [30]. Optically thin plasma is one of the basic requirements of it. An important step of this method is the accurate determination of electron number density $(\mathrm{Ne})$ and plasma temperature $(\mathrm{T})$. Therefore, the incorporations of self-absorption corrections lead to more precise compositions and plasma temperature [31]. Boltzmann relation was used to link intensities of a spectral line between two energy levels as given below: 
Fig. 5 a Emission spectrum of fruit sample ranging of 250 $320 \mathrm{~nm}$. b $320-880 \mathrm{~nm}$
$I=F C^{\mathrm{s}} A_{k} \frac{h c}{\lambda_{k}} \frac{\mathrm{g}_{k}}{P(T)} \exp \left[-\frac{E_{k}}{k_{B} T}\right]$

where $I$ represents the emission line intensity, $F$ is for experimental factor used for collection efficiency, $C^{s}$ shows the composition of emitting species, $P(T)$

Table 1 Values of spectroscopic parameters of Ti (II) lines to make Boltzmann plot for plasma temperature calculation

\begin{tabular}{lllllll}
\hline Ion & $\lambda(\mathrm{nm})$ & $I$ (a.u) & Aki $\left(\mathrm{S}^{-1}\right)$ & $g_{\mathrm{k}}$ & $E_{\mathrm{k}}\left(\mathrm{cm}^{-1}\right)$ & $\begin{array}{l}\ln (\lambda I / \\
\left.A_{\mathrm{k}} g_{\mathrm{k}}\right)\end{array}$ \\
\hline Ti (II) & 319.08 & 3885.01 & $1.41 \times 108$ & 8 & $40,074.67$ & 20.41671 \\
Ti (II) & 322.91 & 2116.66 & $2.93 \times 107$ & 6 & $30,958.58$ & 21.29598 \\
Ti (II) & 323.65 & $13,560.81$ & $1.37 \times 108$ & 8 & $31,113.67$ & 21.31655 \\
Ti (II) & 326.15 & 3544.28 & $1.77 \times 108$ & 12 & $45,908.65$ & 19.92769 \\
Ti (II) & 319.08 & 3885.01 & $1.41 \times 108$ & 8 & $40,074.67$ & 20.41671 \\
\hline
\end{tabular}

represents the partition function, $g_{\mathrm{k}}$ shows statistical weight, $E_{\mathrm{k}}$ is for upper energy level, $k_{\mathrm{B}}$ stands for Boltzmann constant, $T$ represents the temperature, and $A_{\mathrm{k}}$ represents the transition probability. Equation (3)

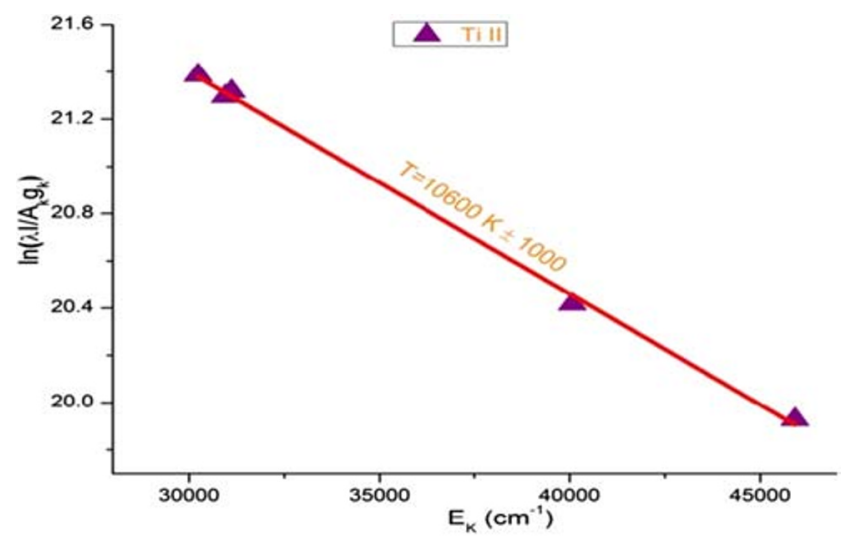

Fig. 6 Boltzmann plot for Ti (II) lines of soil sample 
can be converted to the straight-line equation after taking logarithm on both sides as given below:

$\ln \left[\overline{A_{k}}\right]=\left[-\frac{E_{k}}{k_{B} T}\right]+\ln \left[\frac{F C^{\mathrm{s}}}{P(T)}\right]$

A plot of $\ln \left[\overline{A_{k}}\right]$ vs $\ln \left[\frac{F C^{s}}{P(T)}\right]$ give a straight line with a slope of $\left[-\frac{E_{k}}{k_{B} T}\right]$ and an intercept of $\ln \left[\frac{F C^{s}}{P(T)}\right]$. The experimental factor was determined following Eq. (5):

$F C^{\mathrm{s}}=P(T) e^{q}$

where $F$ stands for the experimental factor that can be determined by normalizing the concentration of all species to unity and can be used for the determination of neutral species., while the concentration of ionized species was determined by using the Saha-Boltzmann equation [32]. The electron number density of an element between two consecutive energy states is related according to the Saha-Boltzmann (Eq. (7));

$\frac{n_{\ddagger+1}^{a}}{n_{\ddagger}^{a}} N_{e}=6.04 \times 1021 T_{e v}^{3} \frac{U_{\ddagger+1}^{a}}{U_{\ddagger}^{a}} \exp \left(-\frac{X_{\ddagger}^{a}}{T_{e v}}\right) \mathrm{cm}$

where $N_{e}$ represents the electron number density of the plasma, $n_{\ddagger}^{a}$ and $n_{\ddagger+1}^{a}$ stand for the electron densities of singly ionized and neutral species respectively, $T_{e v}$ shows the plasma temperature, $X_{\ddagger}^{a}$ is for ionization energies, and $U_{\ddagger+1}^{a}$ and $U_{\ddagger}^{a}$ represent the partition function. The sum of ionized and neutral species gives the total concentration of an element as per Eq. (7) [33] (Fig. 7)

$C_{T}=C_{s}^{I}+C_{s}^{I I}$

where $C_{T}$ is the total concentration of an element, and $C_{s}^{I}$ and $C_{s}^{I I}$ represent the concentrations of neutral and ionized species. Using the above procedure, the compositions obtained for all the samples of ZA is given in Table 2 and also shown in the form of a bar graph as shown in Fig. 8.

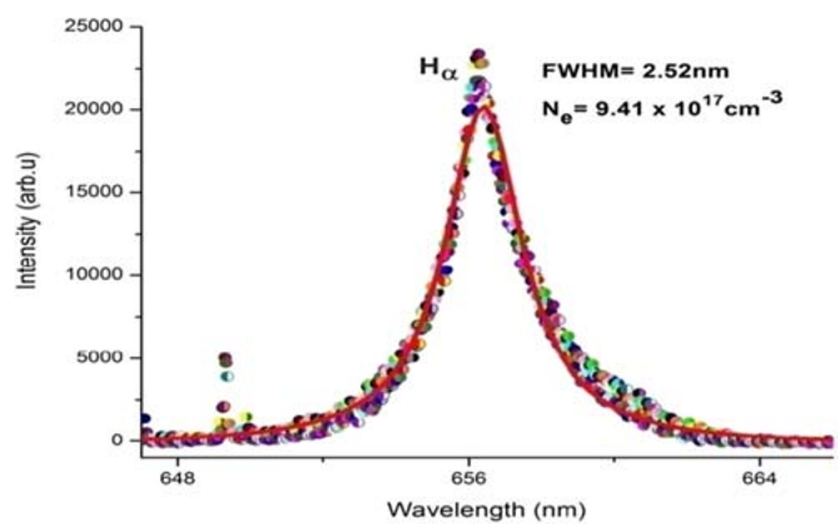

Fig. 7 Stark-broadened profile of $\mathrm{H} \alpha$ line at $656.6 \mathrm{~nm}$ of root sample
Table 2 Elemental compositions of different parts of ZA

\begin{tabular}{llllll}
\hline Elements & Soil (\%) & Root $(\%)$ & Stem $(\%)$ & Fruit $(\%)$ & Leaves $(\%)$ \\
\hline $\mathrm{Mg}$ & 4.62 & 14.17 & 15.73 & 40.55 & 11.47 \\
$\mathrm{Ca}$ & 21.97 & 20.61 & 41.67 & 26.04 & 48.04 \\
$\mathrm{Na}$ & 5.90 & 26.94 & 2.79 & 2.26 & 7.13 \\
$\mathrm{~K}$ & 16.92 & 37.52 & 1.82 & 15.09 & 32.30 \\
$\mathrm{Al}$ & 5.27 & 0.14 & 4.14 & 5.17 & $* * *$ \\
$\mathrm{Ba}$ & 0.12 & 0.20 & 0.85 & $* * *$ & 0.86 \\
$\mathrm{Ti}$ & 18.24 & $* * *$ & $* * *$ & 0.53 & $* * *$ \\
$\mathrm{Fe}$ & 9.43 & 0.30 & 20.80 & 1.56 & 0.20 \\
$\mathrm{Si}$ & 16.18 & 0.06 & 11.89 & 8.79 & $* * *$ \\
$\mathrm{Mn}$ & 0.01 & $* * *$ & $* * *$ & $* * *$ & $* * *$ \\
$\mathrm{Li}$ & 1.34 & 0.06 & 0.32 & 2.26 & $* * *$ \\
\hline
\end{tabular}

$* * *$ Means element is not detected in the sample

Table 2 shows the presence of four major essential elements such as $\mathrm{Ca}, \mathrm{Mg}, \mathrm{K}, \mathrm{Na}$, and a small amount of one trace element $\mathrm{Fe}$ in all the parts of ZA collected from the district Bagh, Azad Kashmir. Calcium is found in higher concentrations in almost all the samples. Five non-essential elements like $\mathrm{Al}, \mathrm{Ba}, \mathrm{Si}, \mathrm{Li}$, and $\mathrm{Ti}$ are also found. These non-essential elements may be carried by the soil to the different parts of the plant because the elemental composition of soil shows the presence of these elements into it. The concentration of determined elements is compared with the permissible limits, and the results reveal that the concentration of quantified metals is below the toxic level.

\subsubsection{Measured elements}

Calcium Calcium is considered one of the most abundant minerals found in the medicinal plants. It is the important mineral of the human body present largely in the teeth, bones, and nails while body fluids, blood, and nerves contain the remaining calcium. It has an important role in the contraction-relaxation of blood vessels and muscles [34]. It is essential for strong bones and teeth for both children and adults. It is also involved in the release of hormones and enzymes playing various roles in the body such as control of asthma [35]. It reduces the problems of heart attack, high blood pressure, and osteoporosis in old age [36]. The investigated values of calcium in all the plant samples were found higher than any other mineral. Hence, these plants may have an effective role in bone disorders and cell signaling for the contraction and relaxation of muscles.

Iron Iron is naturally found in medicinal plants and is considered an essential trace mineral present in the human body. Most of the iron is present in the blood while resting in the bone marrow, muscles, and liver. It is the main component of red blood cells involved in the supply of oxygen and without iron-binding of oxygen with the hemoglobin would not take place resulting in 
Fig. 8 Bar graph showing the elemental compositions of different parts of ZA

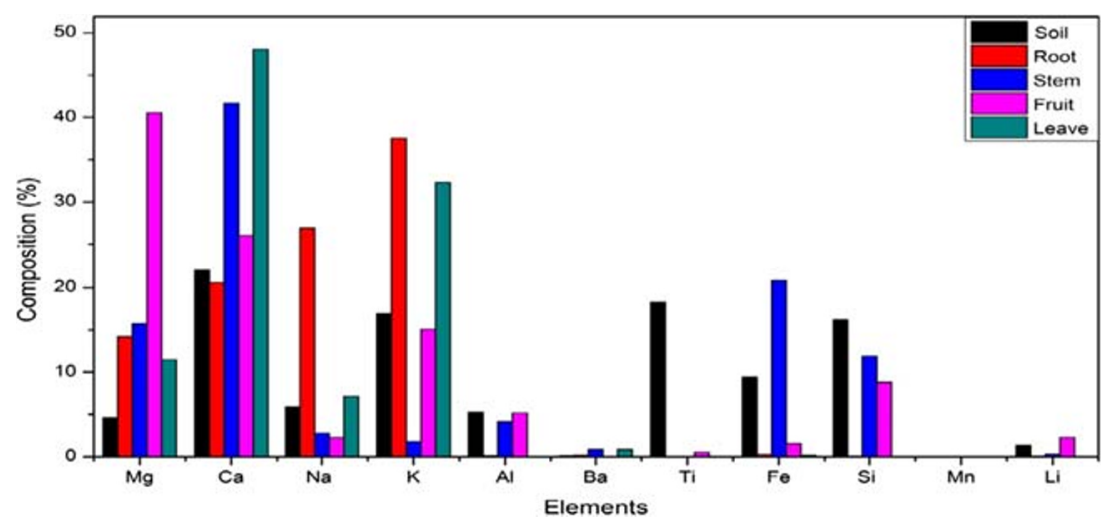

the decreased production of energy necessary for life [37]. It is necessary for the healthy immune system, development, growth, synthesis of connective tissues, and some hormones. This study shows the high concentration of iron for the stem samples of both the village and city. Therefore, the stem of the plant may be suggested to improve the immune response and normal cellular functioning.

Magnesium Magnesium is a very vital element present in the human body and is involved in almost 300 enzymatic reactions occurring in the human body. It works as a co-factor of many crucial enzymes involved in the process of energy metabolism and also needed for RNA and DNA synthesis, protein synthesis, muscular contractions, nerve transmission, insulin metabolism, cardiac excitability, and neuromuscular conductions. Its deficiency may lead to various diseases such as migraine headaches, cardiovascular disease, stroke, constipation, diabetes, and hypertension [38]. It showed that the high concentration of magnesium was found in the fruit sample of the village. Consequently, the fruit of plants may be suggested to treat diabetes, hypertension, and constipation problems.

Potassium Potassium is an essential mineral found in the human body required for the proper functioning of cells, organs, and tissues [39]. It plays a vital role in muscle contraction, digestive, and heart functions. It also maintains cardiac rhythm and reduces hypertension [40]. In the present research, the measured values of potassium are found to be higher for the root samples among other plant samples. The roots of the plant are crucial to the heart functions due to this reason since potassium has the role of maintaining cardiac rhythm.

Sodium Sodium is present in the human body in the lymph nodes and blood. It maintains blood pressure at standard rates [34]. It regulates the nerve and muscle function. However, the high intake of sodium may result in increased tendon reflexes, lethargic condition, and muscle spasticity while low intake may cause headaches, cramps, fatigue, restlessness, and nausea. A small amount of sodium content is found in almost all the plant samples except the root sample of the village containing considerable amounts. Hence, the root of the plant may have a vital role in maintaining the blood pressure and in playing the normal nerve function.

Silicon Silicon is the second most abundant element of the earth crust is carried out by the soil to the medicinal plants. Silicon is known to play a significant role in modulating metabolic and physiological responses both in human and in plant biology. It is involved in the biosynthesis of glycosaminoglycans and collagen needed for the formation of bone matrix [41]. Diets with low silica may result in bone disabilities. It plays a vital function in the absorption of other minerals such as copper and magnesium. It is also involved in maintaining the cycle of lymphocytes ultimately affecting the inflammatory and immune response. Besides this, it is considered a non-essential element. The ingestion of silicon in high levels can cause bone diseases, kidney damage, nephropathy, neuropathy, and liver disease [42]. The estimated level of silicon in all parts of the plant was found to be within the established limits of the toxic level.

Titanium The nonbiological role of titanium is determined in the human body. Most of the titanium passes through the body without absorption, so it poses no harm to the body [43]. In this research, it is found in the negligible amount in only one sample of fruit and its concentration is below the permissible limit.

Barium Barium is not considered an essential trace mineral. Its intake at high levels may cause heart damage, gastrointestinal problems, muscular paralysis, and high blood pressure and may even lead to death [44]. However, only a small concentration of barium is found in various plant samples in the present research which is beyond the toxic levels of $0.009 \mathrm{~g}$ per day [45].

Aluminum Aluminum is the third most abundant element on the earth's crust which poses serious threats to plants and animals including humans [46]. It inhibits the activity of many enzymes such as phosphoxidase, hexokinase, and phosphodiesterase. Its high-level excretion by kidneys may damage them. It replaces the magnesium and iron into the human body resulting in disturbances that are related to the secretory 
functions, cellular growth, and intercellular communication. It causes diseases, such as Alzheimer's disease, and has carcinogenic effects and neurotoxicity [47]. Its small amount is found in the village samples within the permissible limit of $0.001 \mathrm{~g} /$ day [48].

Lithium Plants take up lithium from the soil through the epidermis. It is considered a non-essential element [49]. However, it plays a crucial role to regulate the neurotransmission and thus used for the curing of bipolar disease [50]. It is used in medicines to treat epilepsy, headache, diabetes, and hypertension [51, 52]. Its high-level ingestion may cause visual impairment, nausea, kidney damage, cardiac arrest, and coma [49]. It is present in a very small amount in root, stem, and fruit samples of the village which is beyond the toxic levels.

\section{Conclusion}

In this manuscript, the qualitative and quantitative analysis of all the parts of ZA was carried out by using LIBS. The presence of five essential elements such as $\mathrm{Mg}, \mathrm{Ca}, \mathrm{K}, \mathrm{Fe}$, and $\mathrm{Na}$ while five non-essential elements namely $\mathrm{Al}, \mathrm{Ti}, \mathrm{Si}, \mathrm{Ba}$, and $\mathrm{Li}$ into the plant samples was confirmed by optical emission spectra study. Boltzmann relation was used to link intensities of a spectral line between two energy levels, and the plasma temperatures for all the plant samples are found in the range of $(8000-12,000) \pm 1000 \mathrm{~K}$. The attained result showed that the measured amount of non-essential elements is below the permissible limits. It was observed that the composition of soil contained non-essential elements that can be carried to the different parts of the plant. Conclusively, ZA could be employed as a promising remedy against various diseases without any harmful effects on the human body.

Acknowledgments We are grateful to the Atomic and Laser Plasma Physics Department, National Centre for Physics, Islamabad, Pakistan, for providing the experimental facility.

Funding information Open Access funding provided by the Qatar National Library. The authors received financial support from the Higher Education Commission (HEC) of Pakistan.

Open Access This article is licensed under a Creative Commons Attribution 4.0 International License, which permits use, sharing, adaptation, distribution and reproduction in any medium or format, as long as you give appropriate credit to the original author(s) and the source, provide a link to the Creative Commons licence, and indicate if changes were made. The images or other third party material in this article are included in the article's Creative Commons licence, unless indicated otherwise in a credit line to the material. If material is not included in the article's Creative Commons licence and your intended use is not permitted by statutory regulation or exceeds the permitted use, you will need to obtain permission directly from the copyright holder. To view a copy of this licence, visit http://creativecommons.org/licenses/by/4.0/.

\section{References}

1. U. Dhar, R.S. Rawal, J. Upreti, Setting priorities for conservation of medicinal plants - a case study in the Indian Himalaya. Biological conservation 95, 57-65 (2000)

2. A.M. Tagne et al., Determinants, prevalence and trend of use of medicinal plants among people living with HIV: a cross-sectional survey in Dschang, Cameroon. AIDS and Behavior 23, 2088-2100 (2019)

3. Govind PS (2019) Bioprospecting of some medicinally important plants of lamiaceae from Kinwat and Mahur region of Nanded Maharashtra

4. R. Singh, B. Sharma, in Biotechnological advances, phytochemical analysis and ethnomedical implications of Sapindus species. Traditional uses and ethnomedicinal values of Sapindus spp (Springer, 2019), pp. 17-22

5. R.T. Gahukar, Edible insects collected from forests for family livelihood and wellness of rural communities: a review. Global Food Security, 100348 (2020)

6. S. Nautiyal, K. Smitha, H. Kaechele, in Socio-economic and ecobiological dimensions in resource use and conservation. Medicinal plant biodiversity in India: harnessing opportunities for promoting livelihood and food security (Springer, 2020), pp. 135-169

7. D. Rana, A. Bhatt, B. Lal, O. Parkash, A. Kumar, S.K. Uniyal, Use of medicinal plants for treating different ailments by the indigenous people of Churah subdivision of district Chamba, Himachal Pradesh, India. Environment, Development and Sustainability, 180 (2020)

8. K. Schuhladen, J.A. Roether, A.R. Boccaccini, Bioactive glasses meet phytotherapeutics: The potential of natural herbal medicines to extend the functionality of bioactive glasses. Biomaterials, 119288 (2019)

9. J.M.H. Anal, P. Chase, Trace elements analysis in some medicinal plants using graphite furnace-atomic absorption spectroscopy. Environmental Engineering Research 21, 247-255 (2016). https:// doi.org/10.4491/eer.2016.007

10. B. Mohanta, A. Chakraborty, M. Sudarshan, R.K. Dutta, M. Baruah, Elemental profile in some common medicinal plants of India. Its correlation with traditional therapeutic usage. Journal of Radioanalytical and Nuclear Chemistry 258, 175-179 (2003). https://doi.org/10.1023/a:1026291000167

11. M. Ait-Sidi-Brahim, M. Markouk, M. Larhsini, in New look to phytomedicine. Moroccan medicinal plants as antiinfective and antioxidant agents (Elsevier, 2019), pp. 91-142

12. M.T.A.S. Shazia Jabeen, S.W. Khan, M.Q. Hayat, Determination of major and trace elements in ten important folk therapeutic plants of Haripur basin, Pakistan. Journal of Medicinal Plants Research 4, 559-566 (2010)

13. S. Begaa, M. Messaoudi, Toxicological aspect of some selected medicinal plant samples collected from Djelfa. Algeria Region Biological trace element research 187, 301-306 (2019)

14. C.P. Kala, N.A. Farooquee, U. Dhar, Prioritization of medicinal plants on the basis of available knowledge, existing practices and use value status in Uttaranchal. India Biodiversity \& Conservation 13, 453-469 (2004). https://doi.org/10.1023/B:BIOC.0000006511. $67354.7 f$

15. S. Purohit, K. Joshi, V. Rawat, I.D. Bhatt, S.K. Nandi, Efficient plant regeneration through callus in Zanthoxylum armatum DC: an endangered medicinal plant of the Indian Himalayan region. Plant Biosystems-An International Journal Dealing with all Aspects of Plant Biology, 1-7 (2019)

16. F. Alam, A.J. Shah, Butyrlycholine esterase inhibitory activity and effects of extracts (fruit, bark and leaf) from Zanthoxylum armatum DC in gut, airways and vascular smooth muscles. BMC Complement. Altern. Med. 19, 180 (2019) 
17. N.C. Shah, Chemical composition of the pericarp oil of Zanthoxylum armatum DC. Journal of Essential Oil Research 3, 467-468 (1991). https://doi.org/10.1080/10412905.1991.9697990

18. V. Kumar, S.G.E. Reddy, U. Chauhan, N. Kumar, B. Singh, Chemical composition and larvicidal activity of Zanthoxylum armatum against diamondback moth, Plutella xylostella. Natural Product Research 30, 689-692 (2016). https://doi.org/10.1080/ 14786419.2015 .1036270

19. Bisht D, Chanotiya CS (2011) 2-Undecanone rich leaf essential oil from Zanthoxylum armatum natural product communications 6: 1934578X1100600126 doi:https://doi.org/10.1177/ $1934578 X 1100600126$

20. M.A. Gondal, T. Hussain, Z. Ahmed, A.H. Bakry, Detection of contaminants in ore samples using laser-induced breakdown spectroscopy. Journal of Environmental Science and Health, Part A 42, 879-887 (2007). https://doi.org/10.1080/10934520701373075

21. Jain J, Hartzler D, McIntyre D, Moore J, Crandall D Laser-induced breakdown spectroscopy (LIBS): an emerging spectroscopic technique for shale rock characterization. In, 2019. Unconventional Resources Technology Conference (URTEC)

22. A. Safi, S.H. Tavassoli, G. Cristoforetti, S. Legnaioli, V. Palleschi, F. Rezaei, E. Tognoni, Determination of excitation temperature in laser-induced plasmas using columnar density Saha-Boltzmann plot. Journal of Advanced Research 18, 1-7 (2019)

23. A. Zafar, N. Ahmed, Z. Umar, M. Baig, Spectrochemical analysis of dates available in Pakistan using laser induced breakdown spectroscopy (LIBS) and laser ablation time-of-flight mass spectrometer (LA-TOF-MS). Laser Physics 29, 085602 (2019)

24. A. Das, R. Ghosh, S. Mallik, Saha ionization equation in the early Universe. The Astrophysical Journal 881, 40 (2019)

25. B.B. Soares, E.M. Barboza Jr., E.M. Abreu, J.A. Neto, NonGaussian thermostatistical considerations upon the Saha equation. Physica A: Statistical Mechanics and Its Applications 532, 121590 (2019)

26. Y. Ralchenko, NIST atomic spectra database. Memorie Della Societa Astronomica Italania 8, 96-102 (2005)

27. I. Borgia et al., Self-calibrated quantitative elemental analysis by laser-induced plasma spectroscopy: application to pigment analysis. Journal of Cultural Heritage 1, S281-S286 (2000). https://doi.org/ 10.1016/S1296-2074(00)00174-6

28. J. Van der Mullen, Excitation equilibria in plasmas; a classification. Phys. Rep. 191, 109-220 (1990)

29. J. Bengoechea, J.A. Aguilera, C. Aragón, Application of laserinduced plasma spectroscopy to the measurement of Stark broadening parameters. Spectrochimica Acta Part B: Atomic Spectroscopy 61, 69-80 (2006). https://doi.org/10.1016/j.sab. 2005.11.003

30. J.M. Gomba, C. D'Angelo, D. Bertuccelli, G. Bertuccelli, Spectroscopic characterization of laser induced breakdown in aluminium-lithium alloy samples for quantitative determination of traces. Spectrochimica Acta Part B: Atomic Spectroscopy 56, 695-705 (2001). https://doi.org/10.1016/S0584-8547(01)00208-7

31. L. Sun, H. Yu, Correction of self-absorption effect in calibrationfree laser-induced breakdown spectroscopy by an internal reference method. Talanta 79, 388-395 (2009). https://doi.org/10.1016/j. talanta.2009.03.066

32. E. Tognoni, G. Cristoforetti, S. Legnaioli, V. Palleschi, Calibrationfree laser-induced breakdown spectroscopy: state of the art. Spectrochimica Acta Part B: Atomic Spectroscopy 65, 1-14 (2010). https://doi.org/10.1016/j.sab.2009.11.006

33. V. Unnikrishnan et al., Calibration-free laser-induced breakdown spectroscopy for quantitative elemental analysis of materials. Pramana 79, 299-310 (2012)

34. R.M. Sanjeev Kumar, S. Chaudhary, D.C. Jain, Role of trace elements in Alzheimer's disease. Open Access Library Journal 1, 1-30 (2014)
35. B.R.K. Mohanraj Pattar, C. Nirmala, Determination of some minerals and trace elements in medicinal plants-Acalypha indica (L.), Datura metel (L.) and Tylophora indica (L.) used in thetreatment of ashtma. European Journal of Medicinal Plants 22, 1-11 (2018)

36. S.R. Faizul Haq, H. Ahmad, Z. Iqbal, R. Ullah, Elemental analysis of paeonia emodi and Punica granatum by atomic absorption spectroscopy. American Journal of Biochemistry 2, 47-50 (2012)

37. R.H. Nazanin Abbaspour, R. Kelishadi, Review on iron and its importance for human health. Journal of Research in Medical Sciences 19, 164-174 (2014)

38. U.S.J. Gröber, K. Kisters, Magnesium in prevention and therapy. Nutrients 7, 8199-8226 (2015)

39. K.O. Soetan, C.O. Olaiya, O.E. Oyewole, The importance of mineral elements for humans, domestic animals and plants: a review. African Journal of Food Science 4, 200-222 (2010)

40. N. Ekinci, R. Ekinci, R. Polat, G. Budak, Analysis of trace elements in medicinal plants with energy dispersive X-ray fluorescence. Journal of Radioanalytical and Nuclear Chemistry 260, 127-131 (2004). https://doi.org/10.1023/B:JRNC.0000027071.72742.ee

41. M.A. Farooq, K.-J. Dietz, Silicon as versatile player in plant and human biology: overlooked and poorly understood. Frontiers in Plant Science, 6 (2015). https://doi.org/10.3389/fpls.2015. 00994

42. R.T.K. Jugdaohsingh, N. Qiao, L.A. Cupples, D.P. Kiel, J.J. Powell, Dietary silicon intake is positively associated with bone mineral density in men and premenopausal women of the Framingham Offspring cohort. J. Bone Miner. Res. 19, 297-307 (2004)

43. M.L. Hossen, S.M.A. Islam, M.J. Abedin, S. Akter, O.F. Rasel, M.M. Ahasan, R. Khatun, A.N. Monika, Elemental profile analysis of some traditional medicinal plants of Bangladesh using PIXE technique. Journal of Nuclear and Particle Physics 4, 137-141 (2014)

44. C.K.Y. Ghim Hock Ong, M. Mahmood, S.G. Tan, S. Hamzah, Barium levels in soils and Centella asiatica. Tropical Life Sciences Research 24, 55-70 (2013)

45. H.A. Tülay Küpeli, M. İmamoğlu, Assessment of trace element levels in muscle tissues of fish species collected from a river, stream, lake, and sea in Sakarya, Turkey. The Scientific World Journal 5, 1-7 (2014)

46. W. Barabasz, D. Albinska, M. Jaśkowska, J. Lipiec, Ecotoxicology of aluminium polish. Journal of Environmenta Studies 11, 199-203 (2002)

47. J.T.T. Monisha, A. Naresh, B.B. Mathew, K.N. Beeregowda, Toxicity, mechanism and health effects of some heavy metals. Interdisciplinary Toxicology 7, 60-72 (2014)

48. F. Aguilar, H. Autrup, S. Barlow, L. Castle, R. Crebelli, W. Dekant, K.-H. Engel, N. Gontard, D. Gott, S. Grilli, R. Gürtler, J.-C. Larsen, C. Leclercq, J.-C. Leblanc, F.-X. Malcata, W. Mennes, M.-R. Milana, I. Pratt, I. Rietjens, P. Tobback, F. Toldrá, Scientific opinion of the panel on food additives, flavourings, processing aids and food contact materials (AFC). European Food Safety Authority 754, 1-34 (2008)

49. A. Léonard, P. Hantson, G.B. Gerber, Mutagenicity, carcinogenicity and teratogenicity of lithium compounds. Mutation Research/ Reviews in Genetic Toxicology 339, 131-137 (1995). https://doi. org/10.1016/0165-1110(95)90007-1

50. P.P. Li, Transcriptional mechanisms of lithium action: therapeutic implications. Clinical Neuroscience Research 4, 271-280 (2004). https://doi.org/10.1016/j.cnr.2004.09.005

51. J. Cade, Lithium salts in the treatment of psychotic excitement. Med. J. Aust. 2, 349-352 (1949)

52. L. Kavanagh, J. Keohane, G. Garcia Cabellos, A. Lloyd, J. Cleary, Global lithium sources-industrial use and future in the electric vehicle industry: a review. Resources 7, 57 (2018) 